\title{
A characteristic optic disc appearance associated with myopia in subjects with Graves' ophthalmopathy and in subjects with primary open-angle glaucoma
}

\author{
This article was published in the following Dove Press journal: \\ Clinical Ophthalmology \\ 3 January 2013 \\ Number of times this article has been viewed
}

\author{
Sei Yamazaki' \\ Rishu Inoue ${ }^{2}$ \\ Toshikazu Tsuboi ${ }^{3}$ \\ Ai Kozaki ${ }^{2}$ \\ Toshu Inoue ${ }^{2}$ \\ Toyoko Inoue ${ }^{2}$ \\ Yoichi Inoue ${ }^{2}$ \\ 'Yamazaki Eye Clinic, Shinagawa-ku, \\ Tokyo, Japan; ${ }^{2}$ Olympia Eye Hospital, \\ Shibuya-ku, Tokyo, Japan; ${ }^{3}$ Tsuboi Eye \\ Clinic, Edogawa-ku, Tokyo, Japan
}

\begin{abstract}
Purpose: To determine if qualitatively defining the appearance of optic disc change was a valid characteristic of myopia in subjects with Graves' ophthalmopathy (GO) or primary open-angle glaucoma (POAG).

Methods: We defined typical tilt appearance as the simultaneous presence of the following: an elliptical optic disc, a crescent, unequal sharpness of the cupping margin (horizontally), and nasally displaced vessels in the optic cup. Ninety-two eyes from 92 subjects each with GO or with POAG and no severe complications were included in the study after matching for spherical refractive errors. Using our definition of tilt appearance, two independent observers subjectively judged optic disc photographs. One observer repeated judgments in 70 randomly selected eyes and judgment reproducibility was assessed using kappa statistics. Tilt ratio was used as a quantitative parameter.
\end{abstract}

Results: The numbers of eyes judged as having a typical tilt appearance in the GO group and in the POAG group were $25(27.2 \%)$ and 39 (42.4\%), respectively, by one observer $(P=0.0297)$, and $12(13 \%)$ and $44(47.8 \%)$, respectively, by another observer $(P<0.0001)$. Intra- and interobserver reproducibility of tilt judgment were very good (kappa $=0.93)$ and good (kappa $=0.65$ ), respectively. Tilt ratio did not significantly differ between the two groups. Analytical results including background factors were essentially the same for the two observers: multivariate logistic regression for one observer's judgment showed that the presence of the typical tilt appearance was associated with belonging to the glaucoma group (odds ratio [OR], $6.25 ; P=0.0054$ ), tilt ratio (OR per $0.01,0.77 ; P<0.0001$ ), and spherical refractive error (OR per diopter, $0.80 ; P<0.003)$.

Conclusion: The optic disc feature we designated as typical tilt was associated with myopia, and its frequency was higher in subjects with POAG compared to those with GO.

Keywords: glaucoma, myopia, tilted disc, qualitative definition, tilt ratio, Graves' ophthalmopathy

\section{Introduction}

Myopic eyes are often accompanied by tilted optic discs, which are associated with a series of findings, including a vertically oval optic disc, ${ }^{1-3}$ nasally undermined cupping, ${ }^{1,4}$ nasally displaced vessels in the cupping, ${ }^{1,3,4}$ and the presence of a temporal crescent. ${ }^{1-3,5}$ In our clinical practice in Japan, we observed that an optic disc with the simultaneous presence of the aforementioned features is a common finding and that these features occur more frequently in glaucoma patients than in patients with other ocular diseases. However, there are few reports describing this observation in the literature,
Correspondence: Sei Yamazaki Yamazaki Eye Clinic, I-5-45 Hiratsuka, Shinagawa-ku, Tokyo, |42-005 I Japan

Tel +8I 337826666

Fax +8I 33782665

Email yamazakisei@gmail.com 
which may suggest an association between this characteristic morphology with the pathological process involved in glaucomatous nerve damage.

Several objective parameters are used to evaluate characteristics associated with optic discs in myopic eyes. Among these are the ratio of minimum-to-maximum optic disc diameter (tilt ratio); ${ }^{6}$ the ratio of horizontal-to-vertical optic disc diameter; ${ }^{7,8}$ the degree of optic disc rotation; ${ }^{9-11}$ the ratio of the maximum width of the peripapillary atrophy to the vertical disc diameter, ${ }^{7,8}$ an angle between a line fitted to the optic disc surface and a reference horizontal line in a cross-sectional optical coherence tomography image: ${ }^{10}$ and an area of peripapillary atrophy. ${ }^{11}$ However, findings expressed by these parameters seem to be limited, particularly regarding the characteristic appearances of the cupping and vessels mentioned above, which may be too qualitative to be expressed by objective parameters. Thus, we may be required to qualitatively and/or subjectively identify and define a typical form of myopic tilted disc.

On the other hand, qualitative definitions for tilted discs associated with myopia have been made on the basis of actual nerve tilting observed in stereoscopic views, ${ }^{12-14}$ presence of a crescent, ${ }^{12}$ different steepness of the neuroretinal rim surface according to locations within the disc, ${ }^{12}$ and the ovalness of the optic disc. ${ }^{12,14}$ It is apparent that an established qualitative definition that includes the characteristic appearances of cupping and vessels described above is not available at present. In addition, the reproducibility of procedures defining those characteristics is unknown.

Considering this background, we defined new subjective criteria for defining a typical form of myopic tilted disc and observed its frequency in patients with primary open-angle glaucoma (POAG) and in patients with Graves' ophthalmopathy (GO), which was used as a representative ocular disease other than glaucoma. We also evaluated the reliability of this new judging system and explored potentially relevant factors, including tilt ratio, as objective parameters.

\section{Materials and methods Study design}

In this observational, cross-sectional study, the frequency of the optic disc feature we designated as typical tilt appearance was determined in a group of patients with GO and a group of patients with POAG, including normal-tension glaucoma. The study and data accumulation were carried out with the approval of the institutional review board of the Asai Dermatology Clinic, Yokohama, Kanagawa, Japan, which is an organization that conducts reviews for outside facilities. The data collecting facility
(Olympia Eye Hospital, Shibuya, Tokyo, Japan) specializes not only in glaucoma, but also in thyroid-associated eye diseases, and the number of clinical records in the facility was expected to be sufficient enough to provide candidates who fulfilled the inclusion criteria described below.

The following conditions were considered inclusion criteria for both groups of patients: (1) patients were examined between December 2002 and June 2005 at the Olympia Eye Hospital and clinical records included refractometry, visual acuity testing, slit-lamp biomicroscopy and fundoscopy (both with dilated pupils), and digital fundus photography with high-quality results, taken with a Kowa VX-10i (Kowa Company Ltd, Nagoya, Aichi, Japan) or Canon CR5-NM (Canon Inc, Ota, Tokyo, Japan) camera; (2) the age at onset of each disease $\geq 20$ years; (3) no apparent complication of ocular lesions except their original disease (GO or glaucoma), mild superficial punctate keratopathy, incipient cortical cataract, tessellated fundus, or peripapillary crescents; and (4) no history of intraocular surgery.

Apart from these common criteria, the following were considered as inclusion criteria for patients in the GO group: (1) a diagnosis of GO on the basis of findings including clinical manifestations, endocrinological examinations, and orbital MRI; (2) having undergone applanation tonometry or noncontact tonometry; (3) best-corrected visual acuity in decimal unit $\geq 1.0$; (4) without complicating compressive optic neuropathy attributable to Graves' ophthalmopathy; (5) proptosis, if present, was not sufficiently severe to be indicative for orbital decompression surgery. In terms of NOSPECS classification (classification of Graves' eye disease), ${ }^{15}$ patients with categories $2 \mathrm{~b}, 2 \mathrm{c}, 5 \mathrm{~b}, 5 \mathrm{c}, 6 \mathrm{a}, 6 \mathrm{~b}$, or $6 \mathrm{c}$ were excluded.

In addition to the common criteria above, the following were considered inclusion criteria for patients in the glaucoma group: (1) a diagnosis of POAG or normal-tension glaucoma; (2) having undergone applanation tonometry, gonioscopy, Goldman perimetry, and static perimetry (Octopus program 32 or G2); (3) localized glaucomatous visual field defects earlier than stage 5 of the Aulhorn-Greve classification ${ }^{16}$ that were reproducible in two or more repeated perimetric results; and (4) retinal nerve fiber bundle defect and/or decreased neural rim width in the optic disc, each corresponding to the visual field defect, clearly confirmed from the fundus photographs.

Only one eye per patient was selected so that the spherical refractive error was matched for both groups. The distribution of eyes with a range of spherical refractive errors were divided into groups every three diopters (D). Matching was 
performed because the frequency of the typical tilt appearance was expected to be affected by refractive errors. In patients in whom both eyes were eligible, the eye with the more severe visual field defect was chosen for the glaucoma group and a randomly selected eye was chosen for the GO group.

\section{Definition and evaluation of typical tilt appearance}

We considered the following four elements as features typically observed in optic discs in myopic eyes: (1) a vertically elliptical optic disc contour, ${ }^{1-3}$ (2) the presence of a temporal crescent: ${ }^{1-3,5}$ (3) a blurred cup margin on the temporal side and a clear margin on the nasal side (we designated this as horizontally unequal sharpness of the cupping margin); ${ }^{1,4}$ and (4) retinal vessels displaced nasally and concealed by the nasal rim as they exited the eye (we designated this the nasally displaced vessels in the cupping). ${ }^{1,3,4}$ We then defined the simultaneous presence of all four features as the typical tilt appearance (Figure 1). Although the term "tilt" was originally used to describe a finding in which the optic nerve head is depressed in the temporal margin compared to the nasal margin, optic discs with our definition of typical tilt appearance usually share this three-dimensional characteristic. ${ }^{1}$ Also, our definition is not intended to be applied to findings associated with tilted disk syndrome, ${ }^{17}$ in which inferiorly and nasally tilting of the optic disc is observed.

According to these criteria, two independent, wellexperienced ophthalmologists (TT as observer 1 and RI as observer 2), who were not involved in patient selection, subjectively judged the presence or absence of the typical tilt appearance. When being judged, optic disc photographs were displayed on a liquid crystal display with an arbitrary magnification, and any other clinical information was completely masked. No distinction was required between a crescent that was purely a myopic change or if it was accompanied by atrophic changes attributable to glaucoma or
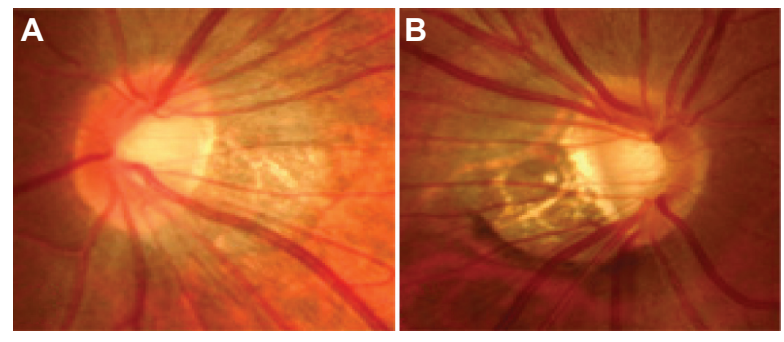

Figure I Optic disc photographs fulfilling our criteria of the typical tilt appearance. (A) A subject with Graves' ophthalmopathy. (B) A subject with glaucoma, in which a nerve fiber layer defect is recognized around the inferior temporal position of the optic disc. aging. ${ }^{18,19}$ To examine intraobserver reliability, one observer (observer 1) reevaluated photographs from 35 subjects randomly selected from each of the GO group and the glaucoma group 1-2 weeks after the initial assessment.

\section{Assessment of the tilt ratio}

Ovality of the optic disc was expressed as the tilt ratio (the ratio of minimum-to-maximum optic disc diameter). ${ }^{6}$ In our measurement, the minimum disc diameter was defined as the width of the optic disc measured on the bisector perpendicular to the maximum disc diameter. An examiner (SY) who was not involved in the judgment of the optic disc appearance performed the diameter measurements using the Shape Tool in the software Photoshop Elements (v 4.0; Adobe Systems Inc, San Jose, CA, USA), while masked to all other clinical information.

\section{Evaluation of data and statistical analyses}

Mann-Whitney $U$ tests and the chi-square tests were used for comparisons between the two groups. Multivariate logistic regression was used to determine the association between the presence of the typical tilt appearance and other factors as explanatory variables that included age, sex, spherical refractive error, intraocular pressure, disc ovality ratio, and group type (GO or glaucoma). For intraocular pressure, the average of two values measured on separate days was used. Although intraocular pressure had not been measured using a unified method for all the subjects, this difference was not considered when included in the analyses. The association between the optic disc appearance and use of ocular hypotensive agents in the glaucoma group subjects was not analyzed because we assumed that such an association was too complex to be evaluated properly in this retrospective study.

Kappa statistics were used to assess intra- and interobserver agreement for the methods used to judge the presence of the typical tilt appearance. Intraobserver kappa values were calculated from the paired data judged by observer 1 . Interobserver kappa values were calculated from the paired data judged by the two observers. The strength of agreement was interpreted on the basis of the kappa values suggested by Altman, ${ }^{20}$ as adapted from the method of Landis and Koch: ${ }^{21}$ kappa values of $0.81-1.00$ indicated very good agreement; $0.61-0.80$, good agreement; $0.41-0.60$, moderate agreement; $0.21-0.40$, fair agreement; and 0.20 or lower, poor agreement. Software JMP (v 7.0.2; SAS Institute Inc, Cary, NC, USA) was used for all statistical analyses. 


\section{Results}

After matching spherical refractive error (Table 1), 92 eyes from 92 patients were selected for the GO group and for the glaucoma group. All 184 patients were considered Japanese based on their names. Characteristics of the subjects of both groups are summarized in Table 2. There were statistically significant but unintentional differences in age and sex between the two groups. The tilt ratio did not show a significant difference between the two groups. None of the patients in the GO group had undergone perimetry because it was not ordered by their physicians. The number of ocular hypotensive ophthalmic solutions used in the glaucoma group subjects was $1 \pm 0.9$ (mean \pm standard deviation) and 33 subjects (35.9\%) did not use any hypotensive agents.

The judgment results of the two independent observers were similar and both showed a significant difference in the frequency of the typical tilt appearance between the two groups (Figure 2): according to the judgment by observer 1, the number of eyes with the typical tilt appearance was $25(27.2 \%)$ in the GO group $(\mathrm{n}=92)$ and $39(42.4 \%)$ in the glaucoma group $(\mathrm{n}=92)(P=0.0297$ between the two groups); according to observer 2 , the number was $12(13 \%)$ in the GO group $(\mathrm{n}=92)$ and $44(47.8 \%)$ in the glaucoma group ( $\mathrm{n}=92)(P<0.0001$ between the two groups).

Table 3 summarizes the kappa statistics calculated from the subjective judgments for the presence of the typical tilt appearance. Interobserver agreement was moderate for the GO group, good for the glaucoma group, and good for both groups as a whole. Intraobserver agreement was very good for the GO group, very good for the glaucoma group, and very good for both groups as a whole.

We analyzed the associations between the background factors and optic disc appearance judged by each observer. Because the analytical results were essentially the same for both observers' judgments, we will present the results from the data judged by observer 1 throughout the rest

Table I Distribution of the spherical refractive errors matched for the Graves' ophthalmopathy group and the glaucoma group

\begin{tabular}{ll}
\hline Spherical refractive errors (diopters) & $\begin{array}{l}\text { Number of eyes } \\
\text { (one eye per patient) }\end{array}$ \\
\hline+3.0 to $<+6.0$ & 2 \\
0 to $<+3.0$ & 22 \\
-3.0 to $<0$ & 20 \\
-6.0 to $<-3.0$ & 24 \\
-9.0 to $<-6.0$ & 19 \\
-12.0 to $<-9.0$ & 4 \\
-15.0 to $<-12.0$ & 1 \\
\hline
\end{tabular}

Table 2 Characteristics of the Graves' ophthalmopathy group and the glaucoma group

\begin{tabular}{|c|c|c|c|}
\hline & $\begin{array}{l}\text { Graves' } \\
\text { ophthalmopathy } \\
\text { group } \\
(n=92)\end{array}$ & $\begin{array}{l}\text { Glaucoma } \\
\text { group } \\
(\mathrm{n}=92)\end{array}$ & $P$-value \\
\hline $\begin{array}{l}\text { Age (years), } \\
\text { mean } \pm S D \text { (range) }\end{array}$ & $\begin{array}{l}38.7 \pm 11.1 \\
(20 \text { to } 67)\end{array}$ & $\begin{array}{l}57.7 \pm 12.9 \\
(29 \text { to } 84)\end{array}$ & $<0.0001$ \\
\hline Female, n (\%) & 77 (83.7) & $44(47.8)$ & $<0.0001$ \\
\hline $\begin{array}{l}\text { Spherical refractive } \\
\text { error }(D) \text {, } \\
\text { mean } \pm \text { SD (range) }\end{array}$ & $\begin{array}{l}-3.38 \pm 3.70 \\
(-12.50 \text { to }+3.50)\end{array}$ & $\begin{array}{l}-3.28 \pm 3.72 \\
(-12.50 \text { to }+3.00)\end{array}$ & $0.868 I$ \\
\hline $\begin{array}{l}\text { Intraocular pressure, } \\
(\mathrm{mmHg}) \text {, } \\
\text { mean } \pm \mathrm{SD} \text { (range) }\end{array}$ & $\begin{array}{l}14.6 \pm 2.7 \\
(9.0 \text { to } 23.0)\end{array}$ & $\begin{array}{l}14.3 \pm 2.6 \\
(9.0 \text { to } 21.0)\end{array}$ & 0.3019 \\
\hline $\begin{array}{l}\text { Tilt ratio, } \\
\text { mean } \pm \text { SD (range) }\end{array}$ & $\begin{array}{l}0.84 \pm 0.08 \\
(0.69 \text { to } 1.00)\end{array}$ & $\begin{array}{l}0.85 \pm 0.10 \\
(0.52 \text { to } 1.00)\end{array}$ & 0.3223 \\
\hline
\end{tabular}

Abbreviations: $\mathrm{SD}$, standard deviation; $\mathrm{N}$, number; $\mathrm{D}$, diopter; $\mathrm{mmHg}$, millimeters of mercury.

of this section. Table 4 summarizes the relevance of the background factors and the judged status of the optic disc appearance in the GO group, and Table 5 for the glaucoma group. Only in the glaucoma group were subjects with the typical tilt appearance significantly younger than subjects without. In both groups, spherical refractive error was more myopic in subjects with the typical tilt appearance than in subjects without. In addition, the tilt ratio was smaller in subjects with the typical tilt appearance than in subjects without in both groups. Table 6 summarizes the results of multivariate logistic regression for the presence of typical tilt appearance in which both groups were analyzed as a whole. Similar to the results of simple comparisons, a greater degree of myopia, smaller disc ovality ratio, and having glaucoma were factors having a significant association with the presence of typical tilt appearance. On the other hand, the effect of age was not significant, contrary to the result of the simple comparison in the glaucoma group (Table 5). Thus, we consider the association of age with the typical tilt appearance in the glaucoma group simply a visual result caused by confounding variables.

\section{Discussion}

We defined a qualitative optic disc feature consisting of four elements as the typical tilt appearance (Figure 1) and observed its frequency in subjects with POAG and in subjects with GO under a condition in which the refractive error was matched for both groups of subjects. According to subjective judgments by each of the two independent observers, the typical tilt appearance was determined to be a familiar finding in both of the current subject groups, and was associated with a 
A

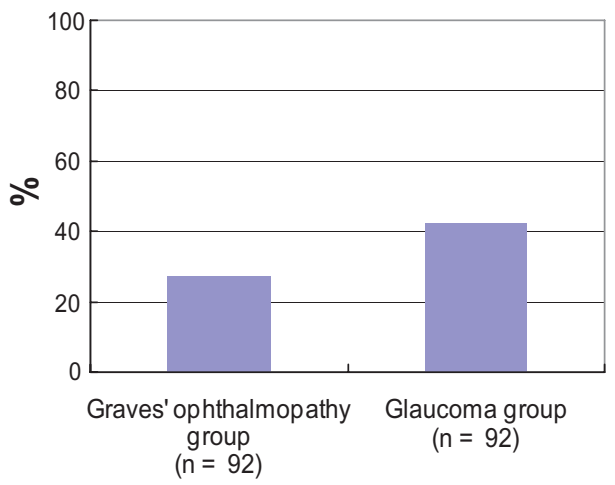

B

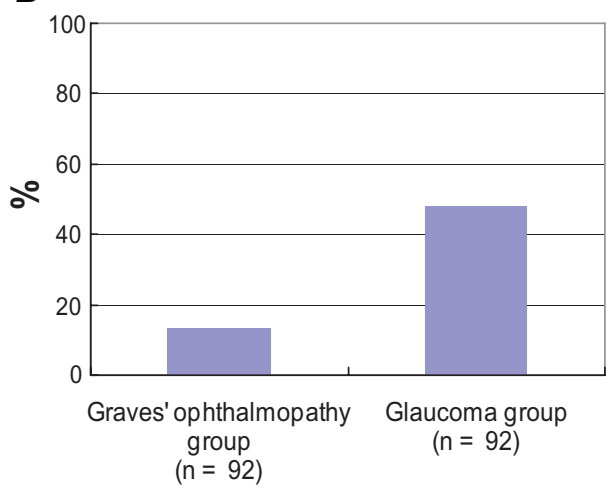

Figure 2 Frequency of eyes judged as having the typical tilt appearance by two independent observers. (A) Observer I; (B) observer 2.

higher degree of myopia and smaller tilt ratios, whereas its frequency was higher in the glaucoma group than in the GO group. Considering that the tilt ratio is an index correlating with the degree of myopia, ${ }^{6}$ our observations may support the assumption that the typical tilt appearance we defined is a characteristic entity of optic disc types seen in myopic eyes. To the best of our knowledge, this is the first attempt to validate a qualitative definition of an optic disc appearance consisting of several features as a typical myopic type. However, instances of optic disc photographs seeming to fulfill our definition may be found in previously published papers that dealt with optic disc findings in Asian subjects with myopia. ${ }^{7,8-11,13,14,22-24}$

On the basis of the results of the kappa statistics (Table 3), the intraobserver and interobserver reliability in this study was sufficient for us to consider the subjective judging system using our criteria acceptable to evaluate an optic disc appearance. In addition, the similarity of two independent observers' judgments with respect to the fact that the frequency of the typical tilt appearance differed significantly between the two groups (Figure 2) may be a finding that supports the reproducibility of the judging system.

The significant association between the tilt ratio and the myopic tilted disc was expected because our criteria included an elliptical optic disc contour, although it was

Table 3 Reliability of the judgments for the presence of the typical tilt appearance

\begin{tabular}{lll}
\hline Group type & $\begin{array}{l}\text { Kappa value (95\% confidence } \\
\text { interval, number of data pairs } \\
\text { used for calculation) }\end{array}$ \\
\cline { 2 - 3 } & Interobserver & Intraobserver \\
\hline Graves' ophthalmopathy & $0.5 \mathrm{I}(0.30-0.7 \mathrm{I}, 92)$ & $0.92(0.77-1.00,35)$ \\
Glaucoma & $0.72(0.57-0.86,92)$ & $0.93(0.80-1.00,35)$ \\
Graves' ophthalmopathy & $0.65(0.54-0.77,184)$ & $0.93(0.83-1.00,70)$ \\
and glaucoma, combined & & \\
\hline
\end{tabular}

judged subjectively. At the same time, this finding suggests that our judging system for the typical tilt appearance succeeded in retaining characteristics resembling the tilt ratio. However, in spite of the similarity of the two parameters, the distribution of the tilt ratio did not show a significant difference between the GO group and the glaucoma group, unlike the frequency of the typical tilt appearance. These dissociative observations may indicate a difficulty in substituting the tilt ratio alone for the qualitative optic disc features that we defined as the typical tilt appearance. In addition, such a difficulty probably arose from essential differences between the two parameters, in that the tilt ratio does not incorporate three of the four elements that the typical tilt appearance does: the temporal crescent, horizontally unequal sharpness of the cupping margin, and nasally displaced vessels in the cupping. Alternatively, it is natural to assume that these three features presented with a higher frequency in the glaucoma group than in the GO group, although both the tilt ratio and the refractive error were distributed equally between the two groups.

The difference in the frequency of the typical tilt appearance between the two groups may suggest some

Table 4 Relevance of background factors on optic disc appearance in the Graves' ophthalmopathy group

\begin{tabular}{|c|c|c|c|}
\hline & \multicolumn{2}{|c|}{ Typical tilt appearance } & \multirow[t]{2}{*}{$P$-value } \\
\hline & $\begin{array}{l}\text { Yes } \\
(n=25)\end{array}$ & $\begin{array}{l}\text { No } \\
(n=67)\end{array}$ & \\
\hline Age (years), mean $\pm S D$ & $37.5 \pm 8.06$ & $39.1 \pm 12.0$ & 0.7822 \\
\hline Female, n (\%) & $22(88.0)$ & $55(82.1)$ & 0.4835 \\
\hline $\begin{array}{l}\text { Spherical refractive error } \\
\text { (D), mean } \pm S D\end{array}$ & $-5.05 \pm 3.28$ & $-2.76 \pm 3.68$ & 0.0081 \\
\hline $\begin{array}{l}\text { Intraocular pressure } \\
(\mathrm{mmHg}) \text {, mean } \pm \mathrm{SD}\end{array}$ & $14.3 \pm 2.7$ & $14.8 \pm 2.8$ & 0.3839 \\
\hline Tilt ratio, mean $\pm S D$ & $0.76 \pm 0.05$ & $0.87 \pm 0.07$ & $<0.0001$ \\
\hline
\end{tabular}

Notes: These results are according to the data judged by observer I. Results were similar for the data judged by observer 2 .

Abbreviations: SD, standard deviation; $\mathrm{N}$, number; $\mathrm{D}$, diopter; $\mathrm{mmHg}$, millimeters of mercury. 
Table 5 Relevance of background factors on optic disc appearance in the glaucoma group

\begin{tabular}{|c|c|c|c|}
\hline & \multicolumn{2}{|c|}{ Typical tilt appearance } & \multirow[t]{2}{*}{$P$-value } \\
\hline & $\begin{array}{l}\text { Yes } \\
(n=39)\end{array}$ & $\begin{array}{l}\text { No } \\
(n=53)\end{array}$ & \\
\hline Age (years), mean $\pm S D$ & $52.1 \pm 11.4$ & $61.8 \pm 12.5$ & 0.0003 \\
\hline Female, n (\%) & $17(43.6)$ & $27(50.9)$ & 0.485 \\
\hline $\begin{array}{l}\text { Spherical refractive error } \\
\text { (D), mean } \pm S D\end{array}$ & $-5.71 \pm 2.70$ & $-1.50 \pm 3.35$ & $<0.000$ I \\
\hline $\begin{array}{l}\text { Intraocular pressure } \\
(\mathrm{mmHg}) \text {, mean } \pm \mathrm{SD}\end{array}$ & $14.6 \pm 2.8$ & $\mid 4.1 \pm 2.4$ & 0.2041 \\
\hline Tilt ratio, mean $\pm S D$ & $0.77 \pm 0.09$ & $0.91 \pm 0.06$ & $<0.0001$ \\
\hline
\end{tabular}

Notes: These results are according to the data judged by observer I. Results were similar for the data judged by observer 2 .

Abbreviations: SD, standard deviation; $\mathrm{N}$, number; $\mathrm{D}$, diopter; $\mathrm{mmHg}$; millimeters of mercury.

underlying mechanisms. For example, in eyes with glaucoma, the crescent may appear or become exaggerated with peripapillary atrophy, ${ }^{18,19}$ and an excavation of the cupping may occur, especially in the nasal region, and these acquired changes could enhance the appearance of myopic tilted disc. Conversely, such changes may not occur as readily in subjects with GO, although, to the best of our knowledge, the association of myopic optic disc changes with GO has not been previously studied. On the other hand, it is possible that the appearance of the tilted discs had already presented to a marked degree and remained relatively stationary from before the onset of the disease in the glaucoma group. Consistent with this possibility, Doshi et $\mathrm{al}^{22}$ hypothesized a causative contribution of tilted disc to the occurrence of nerve fiber damage that corresponded to a diagnosis of glaucoma from their frequent observations of such morphology in a series of young myopic male Chinese patients.

However, the association between group type and the typical tilt appearance in our observation does not prove that

Table 6 Results of multivariate logistic regression for the effects on the presence of typical tilt appearance

\begin{tabular}{lll}
\hline Variable & $\begin{array}{l}\text { Odds ratio } \\
\text { (95\% confidence interval) }\end{array}$ & P-value \\
\hline Age (per year) & $1.00(0.96-1.04)$ & 0.9783 \\
Sex (reference, female) & $0.60(0.20-1.72)$ & 0.3466 \\
$\begin{array}{l}\text { Spherical refractive error } \\
\text { (per diopter) }\end{array}$ & $0.80(0.68-0.92)$ & 0.0030 \\
$\begin{array}{l}\text { Intraocular pressure } \\
\text { (per mmHg) }\end{array}$ & $0.96(0.80-1.15)$ & 0.6648 \\
Tilt ratio (per 0.0I unit) & $0.77(0.70-0.83)$ & \\
Group type (reference, & $6.25(1.82-24.59)$ & 0.0054 \\
Graves' ophthalmopathy) & & \\
\hline
\end{tabular}

Notes: These results are according to the data judged by observer I. Results were similar for the data judged by observer 2 .

Abbreviation: $\mathrm{mmHg}$, millimeters of mercury. a presence of glaucomatous nerve damage is associated with the typical tilt appearance, because the complete normality of visual function of the current subjects in the GO group was not proven as they had not undergone visual field testing. Studies using glaucoma subjects as well as subjects with normal visual function may be worthwhile to determine associations with myopic optic disc changes and glaucomatous nerve damage. The current study only indicates a possibility that the frequency of a typical tilt appearance may differ according to the type of complicating ocular disease.

There are limitations to this study. For instance, in judging optic disc appearances, we employed an all-or-nothing system; thus, some cases judged as not having the typical tilt appearance may have actually had a mild or moderate degree of tilted myopic disc. Methods that can classify the optic disc appearance into more detailed categories may be ideal. Next, intraocular pressure had not been measured using unified methods for all subjects and the use of ocular hypotensive agents in the glaucoma group subjects was not considered in the analyses. As a result, the data pertaining to intraocular pressure may have induced some bias to the analytical results for relevancy of background factors with the optic disc appearances. Thus, whether an associative manner of clinical factors with typical tilt appearance in this study is reproducible needs further confirmation. The accuracy of the refractive error in the GO group may be questionable and present as another limitation because a hypermetropic shift in the refraction can complicate severe cases of the disease, probably because of a flattening of the posterior globe caused by an increased volume of orbital tissues. ${ }^{25}$ However, the GO group in this study did not include patients with severe proptosis indicating decompression surgery or patients with complicating compressive optic neuropathy. Therefore, we considered such a flattening effect of the globe unlikely in our subjects although further studies may be required to verify our estimation.

\section{Conclusion}

We defined an optic disc feature as typical tilt appearance, which was observed to have a considerable association with myopic eyes in subjects with POAG or GO and is thought to represent qualitative characteristics that are difficult to ascertain from the tilt ratio alone; however, the frequency of the typical tilt appearance was higher in subjects with POAG than in those with GO despite matching both groups for spherical refractive error. Further studies may be necessary to confirm our findings as well as to investigate potential associations between typical tilt appearance and other factors. 


\section{Disclosure}

The authors report no conflicts of interest in this work.

\section{References}

1. Tanaka M. [Studies of the crescent, tigroid fundus and cup of the disc. Report I. Fundamental observation]. Nihon Ganka Gakkai Zasshi. 1959;63(8):2137-2143. Japanese.

2. Yanoff M, Sassani JW. Ocular Pathology, 6th ed. Philadelphia: Mosby; 2009:497-527.

3. Curtin BJ. The posterior staphyloma of pathologic myopia. Trans Am Ophthalmol Soc. 1977;75:67-86.

4. Nakase Y. [Primary open angle glaucoma in high myopia. Report 2. Effect of high myopia on glaucomatous cupping of the optic disc]. Nihon Ganka Gakkai Zasshi. 1987;91(4):442-447. Japanese.

5. Spencer WH. Ophthalmic Pathology. An Atlas and Textbook, 3rd ed. Philadelphia: WB Saunders Co; 1985:913-924.

6. Tay E, Seah SK, Chan SP, et al. Optic disk ovality as an index of tilt and its relationship to myopia and perimetry. Am J Ophthalmol. 2005;139(2):247-252.

7. Hyung SM, Kim DM, Hong C, Youn DH. Optic disc of the myopic eye: relationship between refractive errors and morphometric characteristics. Korean J Ophthalmol. 1992;6(1):32-35.

8. Kim TW, Kim M, Weinreb RN, Woo SJ, Park KH, Hwang JM. Optic disc change with incipient myopia of childhood. Ophthalmology. 2012;119(1):21-26.

9. How AC, Tan GS, Chan YH, et al. Population prevalence of tilted and torted optic discs among an adult Chinese population in Singapore: the Tanjong Pagar Study. Arch Ophthalmol. 2009;127(7):894-899.

10. Hwang YH, Yoo C, Kim YY. Characteristics of peripapillary retinal nerve fiber layer thickness in eyes with myopic optic disc tilt and rotation. J Glaucoma. 2012;21(6):394-400.

11. Park HY, Lee K, Park CK. Optic disc torsion direction predicts the location of glaucomatous damage in normal-tension glaucoma patients with myopia. Ophthalmology. 2012;119(9):1844-1851.

12. Lim L, Gazzard G, Chan YH, et al. Corneal biomechanics, thickness and optic disc morphology in children with optic disc tilt. Br JOphthalmol. 2008;92(11):1461-1466.
13. Samarawickrama C, Mitchell P, Tong L, et al. Myopia-related optic disc and retinal changes in adolescent children from Singapore. Ophthalmology. 2011;118(10):2050-2057.

14. Kumar RS, Baskaran M, Singh K, Aung T. Clinical characterization of young Chinese myopes with optic nerve and visual field changes resembling glaucoma. J Glaucoma. 2012;21(5):281-286.

15. Wiersinga WM, Prummel MF, Mourits MP, Koornneef L, Buller HR. Classification of the eye changes of Graves' disease. Thyroid. 1991; 1(4):357-360.

16. Greve EL, Langerhorst CT, van den Berg TTJP. Perimetry and other visual function tests in glaucoma. In: Cairns JE, editor. Glaucoma London: Grune and Stratton; 1986:37-77.

17. Young SE, Walsh FB, Knox DL. The tilted disk syndrome. Am J Ophthalmol. 1976;82(1):16-23.

18. Jonas JB, Fernández MC, Naumann GO. Glaucomatous parapapillary atrophy. Occurrence and correlations. Arch Ophthalmol. 1992; 110(2):214-222

19. Fantes FE, Anderson DR. Clinical histologic correlation of human peripapillary anatomy. Ophthalmology. 1989;96(1):20-25.

20. Altman DG. Practical Statistics for Medical Research. London: Chapman and Hall; 1991:396-439.

21. Landis JR, Koch GG. The measurement of observer agreement for categorical data. Biometrics. 1977;33(1):159-174.

22. Doshi A, Kreidl KO, Lombardi L, Sakamoto DK, Singh K. Nonprogressive glaucomatous cupping and visual field abnormalities in young Chinese males. Ophthalmology. 2007;114(3):472-479.

23. Nakazawa M, Kurotaki J, Ruike H. Long-term findings in peripapillary crescent formation in eyes with mild or moderate myopia. Acta Ophthalmol. 2008;86(6):626-629.

24. Nakazawa T, Fuse N, Omodaka K, Aizawa N, Kuwahara S, Nishida K. Different types of optic disc shape in patients with advanced open-angle glaucoma. Jpn J Ophthalmol. 2010;54(4):291-295.

25. Chandrasekaran S, Petsoglou C, Billson FA, Selva D, Ghabrial R. Refractive change in thyroid eye disease (a neglected clinical sign). Br J Ophthalmol. 2006;90(3):307-309.
Clinical Ophthalmology

\section{Publish your work in this journal}

Clinical Ophthalmology is an international, peer-reviewed journal covering all subspecialties within ophthalmology. Key topics include: Optometry; Visual science; Pharmacology and drug therapy in eye diseases; Basic Sciences; Primary and Secondary eye care; Patien Safety and Quality of Care Improvements. This journal is indexed on

Submit your manuscript here: http://www.dovepress.com/clinical-ophthalmology-journal

\section{Dovepress}

PubMed Central and CAS, and is the official journal of The Society of Clinical Ophthalmology (SCO). The manuscript management system is completely online and includes a very quick and fair peer-review system, which is all easy to use. Visit http://www.dovepress.com/ testimonials.php to read real quotes from published authors. 